\title{
Knowledge and risk perception of oral cavity and oropharyngeal cancer among non-medical university students
}

\author{
Nosayaba Osazuwa-Peters ${ }^{1,2,3,4^{*}}$ and Nhial T. Tutlam ${ }^{4}$
}

\begin{abstract}
Background: To assess non-medical university students' knowledge and perceived risk of developing oral cavity and oropharyngeal cancer.

Methods: A cross-sectional survey was conducted among non-medical students of a private Midwestern university in the United States in May 2012. Questionnaire assessed demographic information and contained 21 previously validated questions regarding knowledge and perceived risk of developing oral cavity and oropharyngeal cancer. Knowledge scale was categorized into low and high. Risk level was estimated based on smoking, drinking, and sexual habits. Bivariate associations between continuous and categorical variables were assessed using Pearson correlation and Chi-square tests, respectively.
\end{abstract}

Results: The response rate was $87 \%$ (100 out of 115 students approached). Eighty-one percent (81\%) had low oral cavity and oropharyngeal cancer knowledge; and only $2 \%$ perceived that their oral cavity and oropharyngeal cancer risk was high. Risk perception was negatively correlated with age at sexual debut, $r(64)=-0.26, p=0.037$; one-way ANOVA showed a marginally significant association between risk perception and number of sexual partners, $F(4$, $60)=2.48, p=0.05$. There was no significant association between knowledge and perception of risk; however, oral cavity and oropharyngeal cancer knowledge was significantly associated with frequency of prevention of STDs $(p<0.05)$. Although $86 \%$ had heard about oral cavity and oropharyngeal cancer, only $18 \%$ had heard of oral mouth examination, and $7 \%$ of these reported ever having an oral cavity and oropharyngeal cancer exam.

Conclusions: Oral cavity and oropharyngeal cancer knowledge and risk perception is low among this student population. Since oral cavity and oropharyngeal cancer incidence is increasingly shifting towards younger adults, interventions must be tailored to this group in order to improve prevention and control.

Keywords: Oral cavity and oropharyngeal cancer, non-medical university students, knowledge, risk perception, sexual habits

\section{Background}

Oral cavity and oropharyngeal cancer is found around the oral cavity and oropharynx, and is the 6th most common cancer in the world, with estimated annual incidence of more than 405, 000 cases [1]. In 2012 in the United States, it was estimated that about 40,250 new cases of oral cancers will be diagnosed [2], thus meeting

\footnotetext{
* Correspondence: nosazuwa@slu.edu

'Brown School, Washington University in St. Louis, 1 Brookings Drive, Saint Louis, MO 63130, USA

${ }^{2}$ Saint Louis University Cancer Center, 3655 Vista Avenue, Saint Louis,

Missouri 63110, USA

Full list of author information is available at the end of the article
}

qualification criteria to be regarded as a common cancer in the United States [3]. They account for almost 3\% of all cancers, and are the 13th most common cancer in the United States $[4,5]$. The causative factors linked to oral cancer include chronic use of tobacco and alcohol, which act independently and synergistically in the etiopathogenesis of the disease $[1,6]$. An increasing number of cases of non-smoking, non-drinking individuals have helped to establish another major causal factor - human papillomavirus (HPV), which was thought to account for up to $23 \%$ of cases of oropharyngeal cancer [7]. A newer study however indicates that at least $70 \%$ of the 
oropharyngeal cancer incidence in the United States, in the last decade, may be causally linked to HPV [8].

Young adults of university age are known to engage in tobacco smoking and alcohol use, and may be frequently exposed to HPV infection, all of which are causal factors for oral cavity and oropharyngeal cancer $[1,6,9]$. Previous studies indicate that university students may have some knowledge of risks associated with tobacco smoking and alcohol [10-12]. However, while HPV remains the most prevalent sexually transmitted infection in the United States, knowledge of HPV among students remains quite low [13]. It has been reported that some college students even misinterpret HPV as HIV [13], and the latter remains a dominant topic of discussion in many sex education curricula across the United States $[13,14]$. Over a decade ago in a Kaiser family survey, only $2 \%$ of the surveyed American population of young people not older than 18 years old, could identify that HPV was a sexually transmitted disease [14]. Knowledge of the link between oral cavity and oropharyngeal cancer and HPV seems even lower. Globally, the few studies that have examined students' knowledge of oral cavity and oropharyngeal cancer only looked at medical and dental students [15-20], who may presumably present with better knowledge scores due to their health-directed training. The only known study that compared undergraduates to medical students and to the general population focused exclusively on HPV as a causal factor for head and neck cancer [21]. No other study, to the best of the author's knowledge, has examined knowledge levels of oral cavity and oropharyngeal cancer exclusively among non-medical students, who may receive greater overall benefit from a customized health education program.

With the recent downward shift in the age of onset of oral cavity and oropharyngeal cancer, especially oropharyngeal cancer, from the typical sixth to seventh decade of life forty years ago $[4,8]$ to the third or fourth decade of life in the last twenty years $[9,22]$, there is a need for increased population based education about oral cavity and oropharyngeal cancer among university students, who represents a sizable population in the United States [23]. This study aims to examine non-medical university students' level of knowledge of oral cavity and oropharyngeal cancer and its risk factors, and to determine university students' perception of their risk of developing oral cavity and oropharyngeal cancer.

\section{Methods}

\section{Study design}

A cross-sectional study was conducted between May and June 2012 in a private, research university in the Midwest. Approval for this study was sought and obtained as protocol ID: 201205057 from the Institutional Review Board of the university prior to commencement of study.

\section{Study participants}

Participants for the study included conveniently sampled male and female students in the university, both undergraduate and graduate students. Students were recruited to voluntarily participate in the study from the university main library and cafeteria. There was no compensation for participating in the study.

\section{Eligibility criteria}

University students 18 years or older were eligible to take part in the study. In addition, participants needed to be able to consent to study in order to participate.

\section{Exclusion criteria}

In order to assess the level of oral cavity cancer knowledge among non-medical university students, all medical, nursing, and public health students were excluded from the study. Additionally, all students who were previously enrolled in a head and neck cancer study, or for those students less than 18 years old, were excluded from the study. In addition, those who had been previously diagnosed with oral head and neck cancer were ineligible to participate.

\section{Data collection \\ Questionnaire}

The study employed a previously validated 58-item, paper-based questionnaire adapted from previous studies $[12,15,16,19]$.

\section{Demographic variables}

The survey included demographic questions such as age, sex, relationship status, race, and educational level.

\section{Risk factor-related variables}

Students were asked "Do you smoke?" "If yes, how many cigarettes do you smoke daily?" and "If you are a current smoker, how long have you been smoking?" Additionally, students who were smokers were asked to gauge their relative risk of developing oral cavity and oropharyngeal cancer compared to other smokers of same age and sex. Students were also asked "Do you drink alcohol?" "How often do you drink?" "If you still drink, how long have you been drinking?" and "If you have stopped drinking, when did you stop?" Finally, students who drank alcohol were asked to gauge perceived oral cavity and oropharyngeal cancer risk.

To elicit risk factors for oral HPV, students were asked the following: "Have you ever had sexual intercourse?", "At what age did you first have sexual intercourse", and "How many sexual partners have you had in your lifetime". Finally, students were asked how frequently they used STD prevention during sexual intercourse, on a scale from "never" to "always". 


\section{Knowledge of oral cavity and oropharyngeal cancer}

Students were asked 14 questions to gauge their knowledge of oral cavity and oropharyngeal cancer. General questions that elicited awareness included "In your opinion, oral cavity and oropharyngeal cancer is more common in which age group?" "In your opinion, in which gender is oral cavity and oropharyngeal cancer more common? and "Does early diagnosis improve recovery from oral cavity and oropharyngeal cancer?" Additionally, some questions focused on the pathophysiology of oral cavity and oropharyngeal cancer, such as: "In your opinion, where are the most likely locations of oral cavity and oropharyngeal cancer?" "In your opinion, which of these could cause oral cavity and oropharyngeal cancer?" "How do you imagine oral cavity and oropharyngeal cancer looks like in the mouth?" "Can oral cavity and oropharyngeal cancer manifest without initial complaint, pain, or symptom?" and "Is oral cavity and oropharyngeal cancer a contagious disease?". There were also Likert scale-styled questions that asked whether students thought HPV infection, tobacco and alcohol use, eating spicy foods, and exposure to sunlight increased an individual's chance of developing oral cavity and oropharyngeal cancer. Answers in the knowledge portion of the questionnaire were then scored as 1 for 'correct' and 0 for 'incorrect'. Each student's answers were summed to create a scale, "knowledge score."

\section{Risk assessment}

There were 4 risk perception questions on a 5-point Likert scale, and participants were asked to compare themselves to other smokers or drinkers of the same age and sex to describe what they thought their chances of developing oral cavity and oropharyngeal cancer in the future were, from most likely to least likely. There was also a question that assessed perceived severity of a potential cancer lesion: "What would you do if you had a painless, abnormal swelling in your mouth for more than 2 weeks?"

\section{Data analysis}

Our final sample size represents a convenience sample of 100 students out of 115 students approached to take the survey, yielding a response rate of $86.96 \%$. Outcome of interest was oral cavity and oropharyngeal cancer knowledge level, a continuous variable which was derived from the knowledge score formed. Pearson's correlation, Chi-Square, and one-way ANOVA assessed bivariate associations between co-variables and outcome of interest. For the purpose of binary logistic regression analyses, knowledge score was categorized as low vs. high; low being knowledge score of $0-7$, and high being $8-14$. Crude measures of association was performed for all covariates in the data. Data was analyzed using SPSS version 20 (Chicago, IL, USA). A two-tailed alpha of .05 was applied as a standard of significance in all analyses.

\section{Results}

There were 100 participants in the study out of 115 students approached, yielding a response rate of $87 \%$. There were $58 \%$ male students in the survey, and $46 \%$ of the students were undergraduates (See Table 1 for demographic characteristics of the population). Demographic data yielded 37\% Caucasians, 37\% Asians, and 19\% African-

Table 1 Sociodemographic characteristics of study population $(\mathrm{N}=100)$

\begin{tabular}{|c|c|c|}
\hline Characteristics & $\mathrm{N}$ & $\%$ \\
\hline \multicolumn{3}{|l|}{ Race } \\
\hline African American & 19 & 19 \\
\hline Asian & 37 & 37 \\
\hline Caucasian & 37 & 37 \\
\hline Hispanic/Latino & 3 & 3 \\
\hline Mixed & 4 & 4 \\
\hline \multicolumn{3}{|l|}{ Age Groups } \\
\hline $16-20$ & 23 & 23 \\
\hline $21-25$ & 44 & 44 \\
\hline $26-30$ & 23 & 23 \\
\hline $31 \&$ over & 10 & 10 \\
\hline \multicolumn{3}{|l|}{ Gender } \\
\hline Male & 58 & 58 \\
\hline Female & 41 & 41 \\
\hline Unknown & 1 & 1 \\
\hline \multicolumn{3}{|l|}{ Smoking Status } \\
\hline Smoker & 3 & 3 \\
\hline Never smoked & 93 & 93 \\
\hline Quit smoking & 3 & 3 \\
\hline Trying to quit & 1 & 1 \\
\hline \multicolumn{3}{|l|}{ Drinking status } \\
\hline Drinker & 65 & 65 \\
\hline Non-drinker & 34 & 34 \\
\hline Stopped drinking & 1 & 1 \\
\hline \multicolumn{3}{|l|}{ Marital Status } \\
\hline Married & 13 & 13 \\
\hline Single & 87 & 87 \\
\hline \multicolumn{3}{|l|}{ Level of study } \\
\hline Undergraduate & 46 & 46 \\
\hline Masters & 34 & 34 \\
\hline Doctoral & 18 & 18 \\
\hline Other & 2 & 2 \\
\hline
\end{tabular}


Americans in the study. A majority of students (93\%) reported that they were non-smokers, while 35\% were non-drinkers. Sixty-eight percent had initiated sexual intercourse, and the youngest age of sexual debut was 14 years old. For oral cavity and oropharyngeal cancer knowledge, $81 \%$ had a low score (between $0-7$ ), while only $19 \%$ had a high score (8-14). Yet, only $2 \%$ perceived that their oral cavity and oropharyngeal cancer risk was high. Risk perception was negatively correlated with age at sexual debut $(r(64)=-0.26, \mathrm{p}=0.037$; see Fig. 1$)$.

There was no significant association between oral cavity and oropharyngeal cancer knowledge and perception of risk; however, knowledge was significantly associated with frequency of prevention of STDs

$F(1,65)=4.90, \mathrm{p}=0.03$, A one-way ANOVA showed a significant positive association between risk perception and number of sexual partners, $F(4,60)=2.48, p=0.05$; see Fig. 2).

Although $86 \%$ claimed to have heard about oral cavity and oropharyngeal cancer, only $7 \%$ of these reported ever having an oral cavity and oropharyngeal cancer examination (See Table 2).

\section{Discussion}

In the population we surveyed, only $3 \%$ of students who participated in this study reported they were current smokers. Previous studies have revealed that between $14 \%$ and $62 \%$ of university students may be considered smokers in the United States [23-27]. We note that this was self-reported data, and social desirability may lead to underreporting. However, another explanation could be that the university where the survey was conducted had implemented a comprehensive smoking ban on campus, and although we do not have information on smoking rates prior to the ban, it has been reported that such bans are associated with decreased smoking rates [28].

We found in our study that oral cavity and oropharyngeal cancer knowledge was not significantly associated with smoking or drinking rates, but was associated with a sexual risk factor for developing oral cavity and oropharyngeal cancer, and with frequency of prevention of STDs. It was also demonstrated that there were significant associations between risk perception and number of sexual partners, as well as the age of sexual debut. This is interesting finding, as literature shows that a significant proportion of young people who are experimenting with oral sex in fact consider oral sex less risky, and/or are more likely to have multiple oral sexual partners than vaginal sexual partners [29]. These sexual habits put them at a higher risk for developing oral cavity and oropharyngeal cancer, especially HPVassociated oropharyngeal cancer. It will remain crucial then to devise strategies to increase the awareness of cancer risks associated with sexual behavior. In this study, a majority of students self-reported that they have never heard of HPV. As HPV is a major driver of overall oral cavity and oropharyngeal cancer incidence, it will be important that information regarding HPV

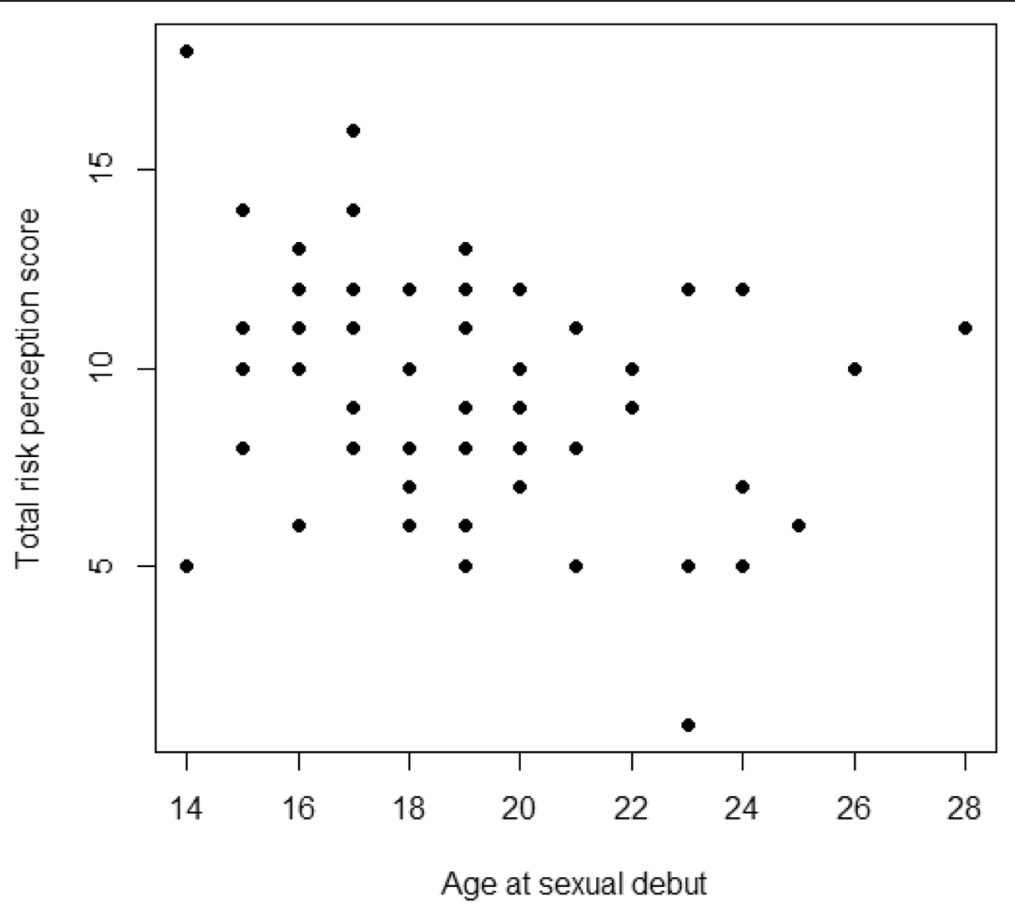

Fig. 1 Correlation between students" perception of risk and age at sexual debut. This figure shows a significant, negative correlation between age at sexual debut and risk perception of students 


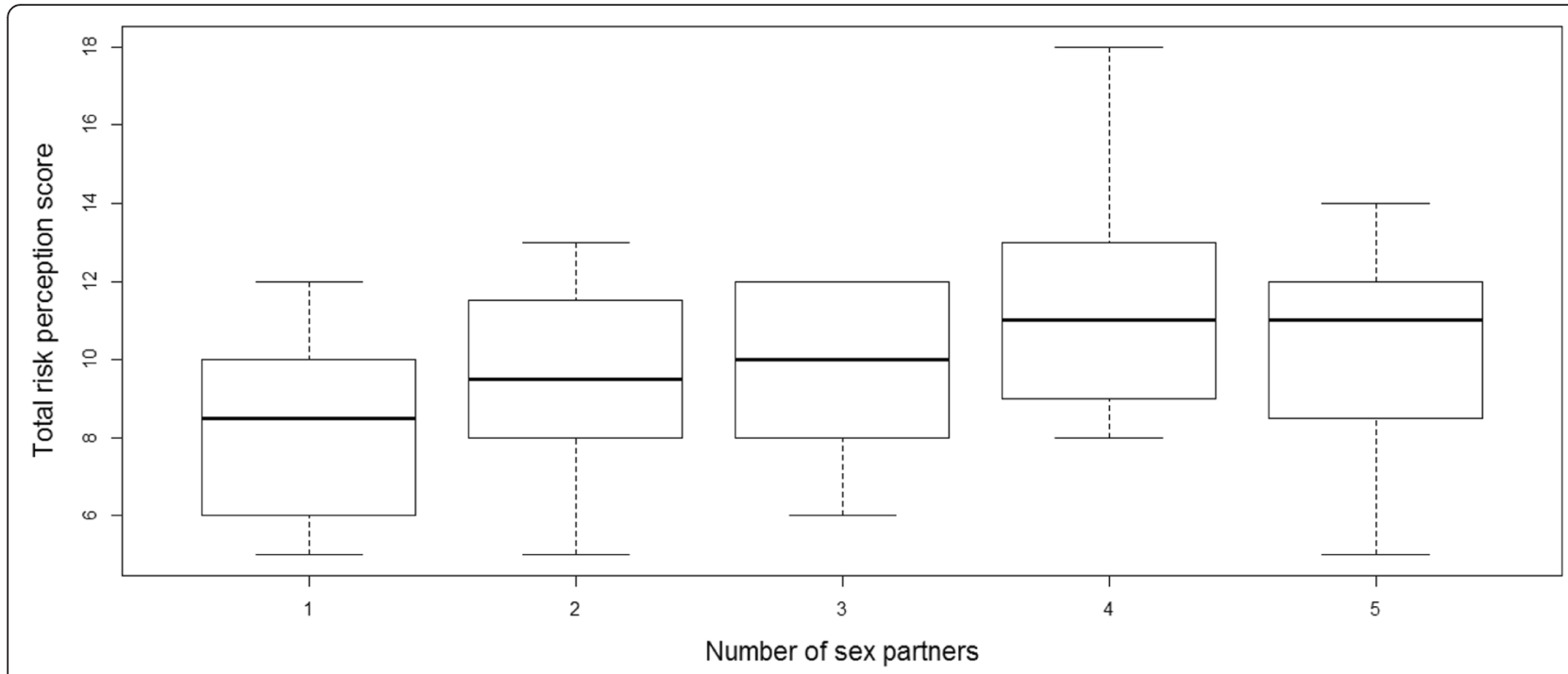

Fig. 2 Association between number of sexual partners and perception of oral cavity and oropharyngeal cancer risk. This figure shows that students with 3 or more sexual partners were more likely to have a high risk perception

and sexual risk taking become an essential component of all oral cavity and oropharyngeal cancer prevention efforts. At least two-thirds of this study population may benefit from interventions stressing the need for HPV vaccines as part of the HPV vaccine catch up age range, which may hold some promise in not only preventing HPV strains that cause cervical cancer, but also oropharyngeal cancers [30, 31].

Table 2 Oral cavity and oropharyngeal cancer and HPV knowledge questions

\begin{tabular}{|c|c|c|c|}
\hline & Yes & No & $\begin{array}{l}\text { Don't } \\
\text { know }\end{array}$ \\
\hline Characteristics & $\begin{array}{l}N \\
(\%)\end{array}$ & N (\%) & N (\%) \\
\hline $\begin{array}{l}\text { Have you heard of oral cavity and } \\
\text { oropharyngeal cancer? }\end{array}$ & $\begin{array}{l}86 \\
(86)\end{array}$ & $12(12)$ & $2(2)$ \\
\hline $\begin{array}{l}\text { Have you ever heard of oral cavity and } \\
\text { oropharyngeal cancer mouth exam? }\end{array}$ & $\begin{array}{l}18 \\
(18)\end{array}$ & $\begin{array}{l}66 \\
(66)\end{array}$ & $16(16)$ \\
\hline $\begin{array}{l}\text { Have you ever had an oral cavity and } \\
\text { oropharyngeal cancer exam? }\end{array}$ & $7(7)$ & $\begin{array}{l}83 \\
(83)\end{array}$ & $10(10)$ \\
\hline $\begin{array}{l}\text { Certain types of HPV lead to oral cavity } \\
\text { and oropharyngeal cancer }\end{array}$ & $\begin{array}{l}63 \\
(63)\end{array}$ & $\begin{array}{l}12 \\
(12)\end{array}$ & $25(25)$ \\
\hline HPV is the same as HIV & $1(1)$ & $\begin{array}{l}76 \\
(76)\end{array}$ & $23(23)$ \\
\hline $\begin{array}{l}\text { Most types of HPV cannot clear } \\
\text { up on their own }\end{array}$ & $\begin{array}{l}61 \\
(61)\end{array}$ & $\begin{array}{l}16 \\
(16)\end{array}$ & $23(23)$ \\
\hline $\begin{array}{l}\text { A person usually has symptoms } \\
\text { when infected with HPV }\end{array}$ & $\begin{array}{l}14 \\
(14)\end{array}$ & $\begin{array}{l}62 \\
(62)\end{array}$ & $24(24)$ \\
\hline $\begin{array}{l}\text { Chance of getting HPV increase } \\
\text { with number of sex partners }\end{array}$ & $\begin{array}{l}75 \\
(75)\end{array}$ & $2(2)$ & $23(23)$ \\
\hline $\begin{array}{l}\text { There is an HPV vaccine for } \\
\text { both men and women }\end{array}$ & $\begin{array}{l}53 \\
(53)\end{array}$ & $\begin{array}{l}24 \\
(24)\end{array}$ & $23(23)$ \\
\hline
\end{tabular}

Only $7 \%$ reported to have had an oral cavity and oropharyngeal cancer examination. The American Cancer Society recommends that oral cavity and oropharyngeal cancer screening should be part of the periodic check for adults when they visit a dentist or other clinicians [32]. And while there remains insufficient evidence to accept or reject routine mouth screenings by primary care physicians in asymptomatic individuals, both the US Preventive Health Services Task Force (USPSTF) and the American Dental Association concede that dentists, otolaryngologists, primary care physicians and other clinicians may decide to screen high-risks groups, based on lifestyle factors or age, and those who may have reasons to suspect a lesion in their mouth [33-35]. This highlights the need for frontline healthcare providers, especially primary care physicians and dentists, to better understand the oral cavity and oropharyngeal cancer risk profiles of their patients, in order to reduce missed opportunities in the clinic for prevention of oral cavity and oropharyngeal cancer via regular oral cancer screenings and education.

There were some limitations in this study. Primarily, the study was non-experimental, and although Caucasians, African-Americans, and Asians were almost equally surveyed, there were few Latinos present in the study. Additionally, study participants stemmed from a single university, yielding a relatively small sample size. Thus, we may not be able to generalize results in the context of university students' population in the United States. Data analysis may have revealed more robust associations between variables if the study had compared medical vs. non-medical students to test whether the assumption that medical 
students are likely to have better oral cavity and oropharyngeal cancer knowledge is true. Notwithstanding these limitations, this project has helped to generate baseline information on the amount of knowledge non-medical students possess regarding oral cavity and oropharyngeal cancer, as well as perception of their risk of developing oral cavity and oropharyngeal cancer. It may be the first study in the United States to exclusively assess oral cavity and oropharyngeal cancer knowledge and knowledge of risk factors (smoking, drinking, and HPV) among a university student population that does not include medical and dental students. Furthermore, in an age where HPV-associated head and neck cancers are increasing in epidemic proportions, our finding that sex-related oral cavity and oropharyngeal cancer risk factors may be more salient among university students than traditional risk factors, such as tobacco and alcohol, is hugely important for future educational interventions, and is worth exploring further.

\section{Conclusions}

Oral cavity and oropharyngeal cancer knowledge and risk perception is low among this student population, and among the risk factors assessed in this population, it is to be concluded that sexual risks are more salient than the traditional oral cavity and oropharyngeal cancer risk factors of tobacco and alcohol use. Therefore, while tobacco cessation efforts and campus-wide smoking bans remain in place to continue addressing smoking rates, these efforts alone may not impact the prevalence of oral cavity and oropharyngeal cancer risk factors among university students. Increasing the awareness about other non-smoking related risk factors, especially those related to sexual behavior, may prove to be more effective in preventing oral cavity and oropharyngeal cancer among university-aged students. Inasmuch as health behavior is associated with risk perception, and oral cavity and oropharyngeal cancer incidence is increasingly shifting towards younger adults, interventions must be tailored to this group in order to improve prevention and control. Prevention of oral cavity and oropharyngeal cancers may pose a difficult challenge without first improving the knowledge of oral cavity and oropharyngeal cancers among high risk groups, particularly university-aged youth in the United States. In addition, since oral cavity and oropharyngeal cancer risk factors are largely prevalent among young adults, it may be of value to increase awareness of cancer risk factors and primary prevention strategies among elementary, middle and high school students, as many of the risk behaviors are likely to be initiated even before college age [36].

\section{Competing interests}

No competing financial or non-financial interests to declare.

\section{Authors' contributions}

Original idea by NOP. NOP designed and conducted the survey and gathered the data. NOP and NTT performed statistical analysis, and interpretation. NOP and NTT produced tables and figures. NOP and NTT wrote the manuscript, and both authors read and approved the final manuscript.

\section{Acknowledgements}

Part of this study was presented at the American College of Epidemiology's Annual Meeting in Louisville, Kentucky on September 21-24, 2013.

We would like to acknowledge the support of Kimberly J Johnson, PhD, Mark A Varvares, MD, FACS, and Mario Schootman, PhD, as well as Rebecca Rohde and Beth B. Tobo, MPH, for helping to proof-read this manuscript.

\section{Author details}

'Brown School, Washington University in St. Louis, 1 Brookings Drive, Saint Louis, MO 63130, USA. ${ }^{2}$ Saint Louis University Cancer Center, 3655 Vista Avenue, Saint Louis, Missouri 63110, USA. ${ }^{3}$ Department of Otolaryngology-Head and Neck Surgery, Saint Louis University, School of Medicine, 6th Floor Desloge Building, 3635 Vista Avenue, Saint Louis, MO 63110, USA. ${ }^{4}$ Department of Epidemiology, Saint Louis University, College for Public Health and Social Justice, 3545 Lafayette Avenue, Saint Louis, Missouri 63108, USA.

Received: 19 May 2015 Accepted: 24 January 2016

Published online: 28 January 2016

References

1. Warnakulasuriya S. Global epidemiology of oral and oropharyngeal cancer Oral Oncol. 2009;45(4-5):309-16.

2. American Cancer Society. Cancer Facts \& Figures 2012. Atlanta: American Cancer Society; 2012.

3. National Cancer Institute. Common cancer types. http://www.cancer.gov/ cancertopics/types/commoncancers.

4. Silverman S. Demographics and occurrence of oral and pharyngeal cancers: the outcomes, the trends, the challenge. J Am Dent Assoc. 2001;132 suppl 1:7S-115.

5. National Cancer Institute, SEER cancer statistics review 1975-2008. http://seer. cancer.gov/archive/csr/1975_2008/

6. Moreno-Lopez LA, Esparza-Gomez GC, Gonzalez-Navarro A, Cerero-Lapiedra R, Gonzalez-Hernandez MJ, Dominguez-Rojas V. Risk of oral cancer associated with tobacco smoking, alcohol consumption and oral hygiene: a case-control study in Madrid. Spain Oral Oncol. 2000;36(2):170-4.

7. Gillison ML, Koch WM, Capone RB, Spafford M, Westra WH, Wu L, et al. Evidence for a causal association between human papillomavirus and a subset of head and neck cancers. J Natl Cancer Inst. 2000;92(9):709-20.

8. Chaturvedi AK, Engels EA, Pfeiffer RM, Hernandez BY, Xiao W, Kim E, et al. Human papillomavirus and rising oropharyngeal cancer incidence in the United States. J Clin Oncol. 2011;29(32):4294-301.

9. Patel SC, Carpenter WR, Tyree S, Couch ME, Weissler M, Hackman T, et al. Increasing incidence of oral tongue squamous cell carcinoma in young white women, age 18 to 44 years. J Clin Oncol. 2011;29(11):1488-94.

10. Torabi MR, Yang J, Li J. Comparison of tobacco use knowledge, attitude and practice among college students in China and the United States. Health Promot Int. 2002;17(3):247-53.

11. Raychowdhury S, Lohrmann DK. Oral cancer risk behaviors among Indiana college students: a formative research study. J Am Coll Health. 2008;57(3): 373-7.

12. Mallett KA, Bachrach RL, Turrisi R. Are all negative consequences truly negative? Assessing variations among college students' perceptions of alcohol related consequences. Addict Behav. 2008;33(10):1375-81.

13. Lambert EC. College students' knowledge of human papillomavirus and effectiveness of a brief educational intervention. J Am Board Fam Pract. 2001;14(3):178-83.

14. Klug SJ, Hukelmann M, Blettner M. Knowledge about infection with human papillomavirus: a systematic review. Prev Med. 2008;46(2):87-98.

15. Chowdhury MT, Pau A, Croucher R. Bangladeshi dental students' knowledge, attitudes and behaviour regarding tobacco control and oral cancer. J Cancer Educ. 2010;25(3):391-5. 
16. Cannick GF, Horowitz AM, Drury TF, Reed SG, Day TA. Assessing oral cancer knowledge among dental students in South Carolina. J Am Dent Assoc. 2005;136(3):373-8.

17. Reed SG, Duffy NG, Walters KC, Day TA. Oral cancer knowledge and experience: a survey of South Carolina medical students in 2002. J Cancer Educ. 2005;20(3):136-42.

18. Boroumand S, Garcia Al, Selwitz RH, Goodman HS. Knowledge and opinions regarding oral cancer among Maryland dental students. J Cancer Educ. 2008;23(2):85-91.

19. Ogden GR, Mahboobi N. Oral cancer awareness among undergraduate dental students in Iran. J Cancer Educ. 2011;26(2):380-5.

20. Carter LM, Ogden GR. Oral cancer awareness of undergraduate medical and dental students. BMC Med Educ. 2007;7:44.

21. White LJ, Creighton Jr FX, Wise JC, Hapner ER. Association between HPV and head and neck cancer: differences in understanding among three distinct populations. Am J Cancer Prevent. 2014;2(1):14-9.

22. Schantz SP, Yu GP. Head and neck cancer incidence trends in young Americans, 1973-1997, with a special analysis for tongue cancer. Arch Otolaryngol Head Neck Surg. 2002;128(3):268-74.

23. Cronk NJ, Harris KJ, Harrar SW, Conway K, Catley D, Good GE. Analysis of smoking patterns and contexts among college student smokers. Subst Use Misuse. 2011:46(8):1015-22.

24. Everett SA, Husten CG, Kann L, Warren CW, Sharp D, Crossett L. Smoking initiation and smoking patterns among US college students. J Am Coll Health. 1999;48(2):55-60.

25. Rigotti NA, Moran SE, Wechsler H. US college students' exposure to tobacco promotions: prevalence and association with tobacco use. Am J Public Health. 2005;95(1):138-44.

26. Rigotti NA, Regan S, Majchrzak NE, Knight JR, Wechsler H. Tobacco use by Massachusetts public college students: long term effect of the Massachusetts Tobacco Control Program. Tob Control. 2002;11 suppl 2:ii20-4.

27. Rigotti NA, Lee JE, Wechsler H. US college students' use of tobacco products: results of a national survey. JAMA. 2000;284(6):699-705.

28. Seo DC, Macy JT, Torabi MR, Middlestadt SE. The effect of a smoke-free campus policy on college students' smoking behaviors and attitudes. Prev Med. 2011;53(4-5):347-52.

29. Gillison ML. Human papillomavirus-related diseases: oropharynx cancers and potential implications for adolescent HPV vaccination. J Adolesc Health. 2008:43(4):S52-60.

30. Osazuwa-Peters N. Human papillomavirus (HPV), HPV-associated oropharyngeal cancer, and HPV vaccine in the United States-Do we need a broader vaccine policy? Vaccine. 2013;31(47):5500-5.

31. Herrero R, Quint W, Hildesheim A, Gonzalez P, Struijk L, Katki HA, et al. Reduced prevalence of oral human papillomavirus (HPV) 4 years after bivalent HPV vaccination in a randomized clinical trial in Costa Rica. Plos One. 2013;8(7), e68329.

32. American Cancer Society. Cancer Facts \& Figures 2015. Atlanta: American Cancer Society; 2015

33. Neville BW, Day TA. Oral cancer and precancerous lesions. CA Cancer J Clin. 2002;52(4):195-215.

34. Moyer VA. Screening for oral cancer: U.S. Preventive Services Task Force recommendation statement. Ann Intern Med. 2014;160(1):55-60.

35. American Cancer Society. American Cancer Society Guidelines for the Early Detection of Cancer. http://www.cancer.org/healthy/findcancerearly/ cancerscreeningguidelines/american-cancer-society-guidelines-for-the-earlydetection-of-cancer.

36. Eaton DK, Kann L, Kinchen S, Shanklin S, Flint KH, Hawkins J, et al. Youth risk behavior surveillance-United States, 2011. MMWR Surveill Summ. 2012;61(4): $1-162$.

\section{Submit your next manuscript to BioMed Central and we will help you at every step:}

- We accept pre-submission inquiries

- Our selector tool helps you to find the most relevant journal

- We provide round the clock customer support

- Convenient online submission

- Thorough peer review

- Inclusion in PubMed and all major indexing services

- Maximum visibility for your research

Submit your manuscript at www.biomedcentral.com/submit
Biomed Central 